\title{
Validating reference microRNAs for normalizing qRT-PCR data in bovine oocytes and preimplantation embryos
}

\author{
Mahdi Mahdipour ${ }^{1}$, Helena T.A. van Tol ${ }^{1}$, Tom A.E. Stout ${ }^{1,2}$ and Bernard A.J. Roelen ${ }^{1,2^{*}}$
}

\begin{abstract}
Background: MicroRNAs (miRNAs) are small noncoding RNAs that act as post-transcriptional regulators of gene targets. Accurate quantification of miRNA expression using validated internal controls should aid in the understanding of their role in epigenetic modification of genome function. To date, most studies that have examined miRNA expression levels have used the global mean expression of all expressed genes or the expression of reference mRNAs or nuclear RNAs for normalization.
\end{abstract}

Results: We analyzed the suitability of a number of miRNAs as potential expression normalizers in bovine oocytes and early embryos, and porcine oocytes. The stages examined were bovine oocytes at the germinal vesicle (GV) and metaphase II stages, bovine zygotes, 2, 4 and 8 cell embryos, morulae and blastocysts, as well as porcine cumulus oocyte complexes, GV, metaphase I and II oocytes. qRT-PCR was performed to quantify expression of miR-93, miR-103, miR-26a, miR-191, miR-23b, Let-7a and U6 for bovine samples and miR-21, miR-26a, miR-93, miR-103, miR-148a, miR-182 and miR-191 for porcine oocytes. The average starting material for each sample was determined using specific standard curves for each primer set. Subsequently, geNorm and BestKeeper software were used to identify a set of stably expressed miRNAs. Stepwise removal to determine the optimum number of reference miRNAs identified miR-93 and miR-103 as the most stably expressed in bovine samples and miR-26a, miR-191 and miR-93 in porcine samples.

Conclusions: The combination of miR-93 and miR-103 is optimal for normalizing miRNA expression for qPCR experiments on bovine oocytes and preimplantation embryos; the preferred combination for porcine oocytes is miR-26a, miR-191 and miR-93.

Keywords: Reference miRNA, Bovine, Porcine, Oocyte, Embryo, qRT-PCR

\section{Background}

During mammalian embryogenesis, primordial germ cells migrate to the genital ridge, and the somatic cells in these structures direct germ cell development [1]. In females, after several mitotic divisions the germ cells develop into primary oocytes, enter meiosis and then arrest at prophase I of the first meiotic division. Oocytes of most mammalian species resume meiosis only shortly before ovulation, and arrest again at the metaphase II stage until activated by sperm penetration at fertilization [2]. After fertilization, the zygote embarks on a series of

\footnotetext{
* Correspondence: b.a.j.roelen@uu.nl

'Department of Farm Animal Health, Faculty of Veterinary Medicine, Utrecht University, Yalelaan 104, 3584CM, Utrecht, The Netherlands

${ }^{2}$ Department of Equine Sciences, Faculty of Veterinary Medicine, Utrecht University, Yalelaan 104, 3584CM, Utrecht, The Netherlands
}

cleavage divisions to form a multicellular embryo. Depending on the species, the embryonic genome is switched on somewhere between the 2- and 8-cell stages [3-6].

MicroRNAs (miRNAs) are small (19-24 nucleotides) non-coding RNAs, that have been identified in plants, animals and viruses and are involved in the regulation of gene expression at both transcriptional and posttranscriptional levels. They bind to the 3'-UTR of their target mRNA and either inhibit translation or induce degradation of that mRNA [7-10]. miRNAs are key components of gene regulation and are involved in various biological processes such as control of the cell cycle, apoptosis [11, 12], and regulation of developmental processes and embryogenesis $[13,14]$. Aberrant expression of miRNAs can lead to various disease states, including tumor formation [15-17]. Several studies have demonstrated the 
presence of miRNAs in oocytes and established their importance during oocyte maturation and early embryo development [18-23].

One issue that has not yet been fully addressed however, is the accurate quantification of miRNA expression levels. Quantitative reverse transcription PCR (qRT-PCR) is a sensitive and relatively rapid method to examine gene expression levels in small numbers of cells [24]. In order to accurately determine gene expression levels by qRT-PCR, however, it is important to correct for factors that could influence starting or final RNA levels such as differences in the amount or nature of starting material, and the methods of RNA isolation and cDNA synthesis. In addition minimizing technical variation is essential to identifying real expression differences between samples [25]. Thus the accuracy of expression data, and any conclusion based on expression patterns, is highly dependent on valid normalization strategies [26].

Gene expression levels can be normalized using stably expressed genes, referred to as reference genes. These genes are generally selected on the basis of having the least variation in expression across the tissues of interest. Although genes coding for basic metabolic processes, such as that coding for glyceraldehyde-3 phosphate dehydrogenase (GAPDH), are constitutively expressed in many cells and have been used as reference genes for a variety of cell and tissue types in various species, their selection does require validation by examining and determining the most stable potential reference genes within the cells, tissue or samples of interest [25, 27].

Although several miRNAs and nuclear RNAs have been used for normalizing levels of miRNA expression determined by qRT-PCR, there are no convincing data demonstrating their stable expression in bovine oocytes and embryos. In the present study, we examined the expression of various miRNAs and a nuclear RNA in order to identify the most stably expressed miRNAs in bovine oocytes and pre-implantation embryos, and porcine oocytes of different maturation stages.

\section{Methods}

\section{Oocyte collection, maturation and fertilization}

Bovine ovaries were collected from a slaughterhouse, and transported in a polystyrene box; they arrived at the laboratory within $2 \mathrm{~h}$ after slaughter. After washing, the ovaries were transferred to a flask containing $0.9 \% \mathrm{NaCl}$ supplemented with penicillin/streptomycin $(1 \mathrm{ml} / \mathrm{L})$ and maintained at $30{ }^{\circ} \mathrm{C}$ in a water bath. Cumulus oocyte complexes (COCs) were collected by aspirating the contents of 2-8 mm diameter follicles, and selected under a microscope based on the presence of a multilayered cumulus complex. Selected COCs were matured and fertilized as described previously [28]. In short, oocytes were cultured in maturation medium and fertilized after 23-24 $\mathrm{h}$ of maturation with $1 \times 10^{6} / \mathrm{ml}$ sperm from a bull of proven fertility. The cumulus cells were removed by vortexing 18-22 $\mathrm{h}$ after sperm addition, and the oocytes were transferred to pre-equilibrated synthetic oviductal fluid (SOF). Presumptive zygotes were cultured in a humidified incubator at $38.5^{\circ} \mathrm{C}, 5 \% \mathrm{CO}_{2}$ and $7 \% \mathrm{O}_{2}$. At day 5 of culture, cleaved embryos were transferred to fresh SOF and cultured until day 8. Oocytes and embryos were collected at $0 \mathrm{~h}$ (germinal vesicle), $23 \mathrm{~h}$ (metaphase II) of maturation, $20,32,38,56 \mathrm{~h}$ post fertilization (for zygote, 2,4 and 8 cell embryo), day 5 (morula) and day 8 (blastocyst) then stored at $-80{ }^{\circ} \mathrm{C}$ until small RNA extraction. Only those oocytes and embryos were collected that were indeed at the correct developmental stages as presence of arrested cells or embryos could alter the presence of miRNAs. Porcine ovaries were processed similarly to bovine ovaries. COCs were recovered by aspiration from follicles with a diameter of 2-5 mm. Selected COCs were matured as described previously [29]. Cumulus cells were removed after 24 or $48 \mathrm{~h}$ of maturation to yield MI and MII oocytes respectively.

\section{miRNA isolation and CDNA synthesis}

Isolation of total miRNA was performed using the miRCURY RNA Isolation Kit (300110; Exiqon, Vedbaek, Denmark), with some modifications. Briefly, oocytes and embryos (20 per group) were lysed in $350 \mu$ lysis buffer, mixed with $200 \mu \mathrm{l}$ of $100 \%$ ethanol and pipetted directly onto an RNA-binding column. After washing, miRNA was eluted using $50 \mu$ l elution buffer followed by a second elution with $50 \mu \mathrm{l}$ of RNAse-free water. The eluent was concentrated using the RNeasy MinElute Cleanup Kit (74204, Qiagen, Valencia, CA, USA). Reverse transcription (RT) was performed using a miRCURY LNA, Universal cDNA Synthesis Kit II, (203301, Exiqon) in a total volume of $20 \mu \mathrm{l}$ made up of $10 \mu \mathrm{l}$ sample RNA, $4 \mu \mathrm{l} 5 \mathrm{x}$ buffer, $2 \mu \mathrm{l}$ RNAse-free water, $2 \mu \mathrm{l}$ RNA spike (UniSp6) and $2 \mu \mathrm{l}$ enzyme mix. The mixture was incubated for $1 \mathrm{~h}$ at $42{ }^{\circ} \mathrm{C}$, followed by $5 \mathrm{~min}$ at $80^{\circ} \mathrm{C}$ before storage at $-20^{\circ} \mathrm{C}$.

\section{Quantitative RT-PCR}

Quantitative RT-PCR was performed on three independent cDNA samples in duplicate. Samples were quantified simultaneously in one run on a 96-well plate using a real-time PCR detection system (MyIQ Single-color Real-Time PCR Detection System; Bio-Rad Laboratories, Hercules, CA, USA). Standard curves were made from serial dilutions of cDNA. The qRT-PCR reaction mixture

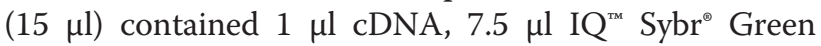
Supermix (Bio-Rad Laboratories), $1.5 \mu \mathrm{l}$ primer mix and $5 \mu \mathrm{l}$ RNAse-free water. Initial denaturation took place at $95{ }^{\circ} \mathrm{C}$ for $10 \mathrm{~min}$, followed by 45 cycles each consisting of $10 \mathrm{~s}$ at $95^{\circ} \mathrm{C}$ and $60 \mathrm{~s}$ at $60{ }^{\circ} \mathrm{C}$ (ramp rate of $1.6{ }^{\circ} \mathrm{C} / \mathrm{s}$ ). Melting curves were plotted at the end of each cycle series to verify the purity of the products. Progressive 
dilutions of cDNA from 450 bovine oocytes and 415 porcine oocytes were used to determine primer efficiencies and to generate the standard curves for each primer pair. The relative starting quantity for each experimental sample was calculated based on the standard curve made for each primer pair. Primers used for qRT-PCR were designed and obtained through the Exiqon website (http://www.exiqon.com).

\section{Statistical analysis}

During qPCR amplification, amplification curves were generated for each sample, and subsequently a quantification cycle $(\mathrm{Cq})$ value was calculated for each amplicon. Relative expression was calculated using each amplicon's specific standard curve. These values were assessed using geNorm Version 3.5 [25] and BestKeeper Version 1 [30] to investigate expression stability. Using the geNorm software, the stability value $(\mathrm{M})$ based on the average pairwise variation between all studied genes was calculated, whereas for BestKeeper a pair-wise correlation analysis of all pairs of candidate genes was determined and geometric expression means were calculated.

Results are presented in bar graphs as means \pm standard error. Differences of miRNA expression in different samples were tested by ANOVA with a post hoc Fisher's Least Significant Difference (LSD) test. A probability (P) below 0.05 was considered significant.

\section{Results}

\section{Expression of candidate housekeeping miRNAs}

The miRNAs examined in this study were selected primarily because their use and expression has been described in other species or tissues, in which they had relatively stable expression levels [26, 31-38]. Alternatively, their in-silico identified messenger RNA targets have important roles in general cell function such as RNA transcription suggesting that they could potentially act as reference miRNAs for normalizing expression data. In bovine samples, the expression of miR-23b, miR26a, miR-93, miR-103, miR-191, Let-7a and the nuclear RNA U6 was examined. In porcine samples, the miRNAs identified as fluctuating least in bovine samples, namely miR-26a, miR-93, miR-103 and miR-191 were examined together with miR-21, miR-148a, and miR-182.

Identification of putative messenger RNA targets for miR-21, miR-23, miR-148a and miR-182 using gene ontology analysis suggested that these miRNAs may play important roles in regulation of cell development, morphogenesis, differentiation and apoptosis (data not shown).

The average amplification efficiency of the candidate reference miRNAs was $91.7 \%( \pm 7.7)$ with an average coefficient of determination $\left(r^{2}\right)$ of $0.994( \pm 0.005)$. Single peaks in the melting curves (data not shown) confirmed the uniqueness of PCR products. The absolute expression of both miRNAs and the nuclear RNA U6 in bovine oocytes and embryos varied considerably, even between samples from similar developmental stages. To exclude the possibility that the differences in expression levels were due to differences in cDNA synthesis the expression of UniSp6 that was used as a spike-in was examined in a different set of samples that was collected and treated exactly the same as the experimental samples. The levels of UniSp6 did not change throughout the stages analysed indicating similar cDNA synthesis efficiency (Additional file 1: Figure S1). Among the miRNAs tested for bovine oocytes and embryos, miR-93 and miR-103 showed similar and more stable expression patterns. In porcine samples,

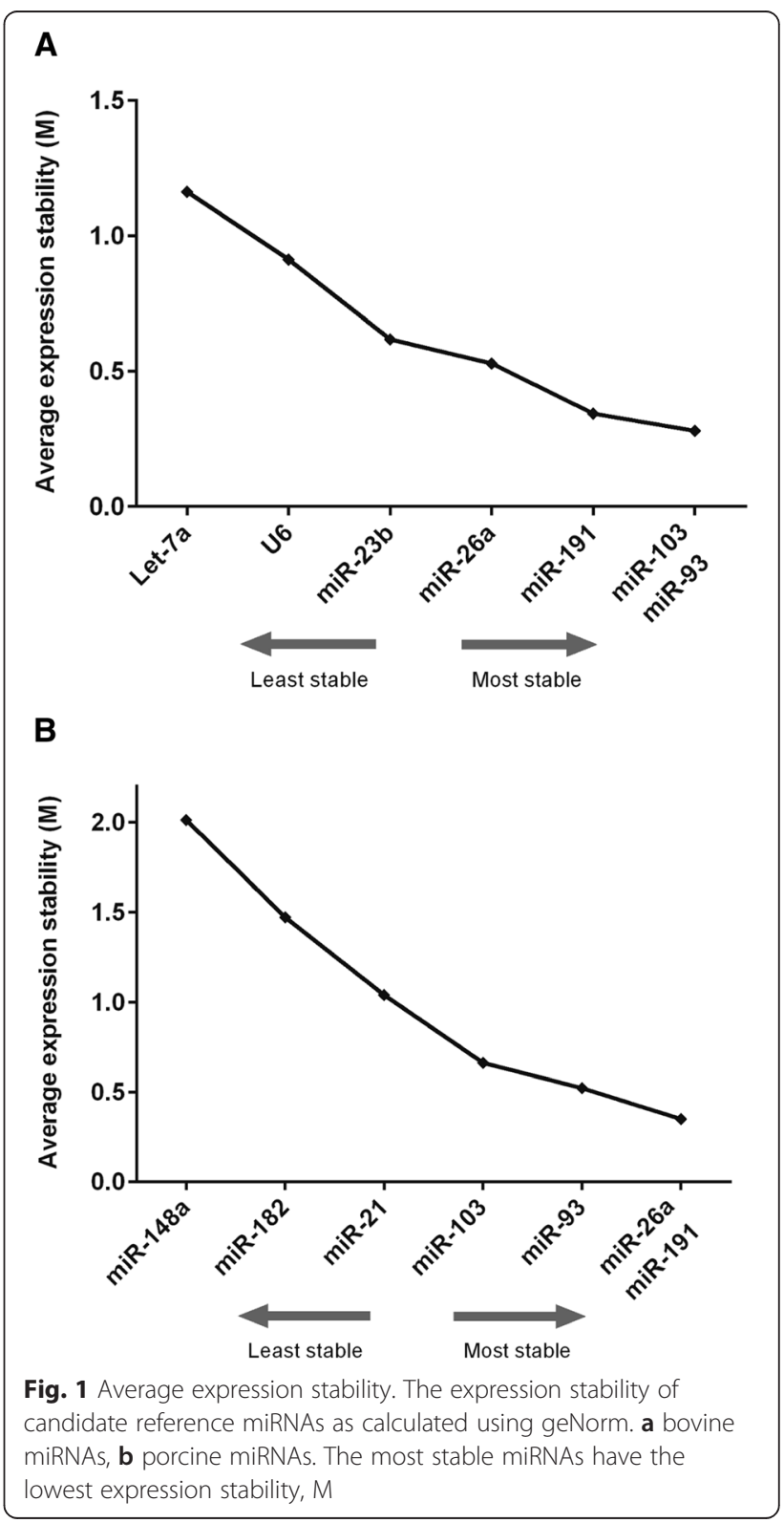


Table 1 Pearson correlation coefficient for bovine data

\begin{tabular}{lllllll}
\hline vs. & miR-23b & miR-26a & miR-93 & miR-103 & miR-191 & Let-7a \\
\hline miR-26a & 0.772 & - & - & - & - & - \\
$p$-value & 0.001 & - & - & - & - & - \\
miR-93 & 0.837 & 0.852 & - & - & - & - \\
$p$-value & 0.001 & 0.001 & - & - & - & - \\
miR-103 & 0.805 & 0.872 & 0.981 & - & - & - \\
$p$-value & 0.001 & 0.001 & 0.001 & - & - & - \\
miR-191 & 0.822 & 0.793 & 0.967 & 0.963 & - & - \\
$p$-value & 0.001 & 0.000 & 0.001 & 0.001 & - & - \\
Let-7a & 0.317 & 0.330 & 0.213 & 0.213 & 0.185 & - \\
$p$-value & 0.131 & 0.115 & 0.319 & 0.319 & 0.388 & - \\
U6 & 0.252 & 0.258 & 0.411 & 0.410 & 0.428 & - \\
$p$-value & 0.235 & 0.224 & 0.046 & 0.046 & 0.037 & - \\
BestKeeper vs. & miR-23b & miR-26a & miR-93 & miR-103 & miR-191 & 0.140 \\
coeff. of corr. [r] & 0.841 & 0.861 & 0.947 & 0.945 & 0.932 & - \\
$p$-value & 0.001 & 0.001 & 0.001 & 0.001 & 0.001 & - \\
\hline
\end{tabular}

the average $E$ and $R^{2}$ values were $97.4 \%( \pm 10.9)$ and 0.989 $( \pm 0.010)$ respectively. In these samples, expression of miR26a, miR-191, miR-93 and miR-103 were most similar.

The absolute expression levels of most miRNAs were highest in bovine morula and blastocyst samples (Additional file 2: Figure S2) and porcine COC samples (Additional file 3: Figure S3). This is most likely caused by higher total RNA levels in those samples.

\section{Expression stability}

To find the optimal set of reference miRNAs in each species, miRNA expression was analyzed using the software packages geNorm and BestKeeper.

Using geNorm, the average expression stability (M) for the miRNAs was calculated by stepwise exclusion of the miRNA with the lowest expression stability. High variation in expression elevates $M$ values and indicates low stability, whereas low $M$ values indicate high expression stability. In cattle oocytes and embryos, miR-103 and miR93 showed the lowest $M$ value, and thus highest stability, whereas Let-7a and U6 expression was more variable (Fig. 1a). In porcine samples, miR-26a and miR-191 had the lowest $M$ values, followed by miR-93 (Fig. 1b).

Using BestKeeper, pairwise correlation of the expression of miRNAs was analyzed via raw quantification cycle values. The geometric mean of the best combination of candidates was calculated to establish a BestKeeper index. In cattle, the BestKeeper outcome indicated expression levels of miR-93, miR-103 and miR-191 as having the highest coefficient of correlation $[\mathrm{r}]$ indicator of a linear relationship between two variables (Table 1). These miRNAs also demonstrated the highest coefficient of determination $\left[\mathrm{r}^{2}\right]$, which is an index of the proportion of the fluctuations of one variable from the other (Table 2). The combination

Table 2 Regression analysis

\begin{tabular}{|c|c|c|c|c|c|c|c|}
\hline & miR-23b & miR-26a & miR-93 & miR-103 & miR-191 & Let-7a & U6 \\
\hline & vs. & vs. & vs. & vs. & vs. & vs. & vs. \\
\hline & BK & BK & BK & BK & BK & BK & BK \\
\hline coeff. of corr. [r] & 0.841 & 0.861 & 0.947 & 0.945 & 0.932 & 0.412 & 0.582 \\
\hline coeff. of det. [r^2] & 0.707 & 0.741 & 0.897 & 0.893 & 0.869 & 0.170 & 0.339 \\
\hline intercept [CP] & 6.523 & 1.629 & -6.823 & -5.029 & -8.145 & 14.409 & -0.709 \\
\hline slope [CP] & 0.838 & 0.960 & 1.299 & 1.163 & 1.353 & 0.559 & 0.802 \\
\hline $\mathrm{SE}[C P]$ & \pm 0.623 & \pm 0.655 & \pm 0.508 & \pm 0.464 & \pm 0.607 & \pm 1.428 & \pm 1.293 \\
\hline$p$-value & 0.001 & 0.001 & 0.001 & 0.001 & 0.001 & 0.046 & 0.003 \\
\hline Power $[x$-fold $]$ & 1.680 & 1.787 & 2.048 & 1.890 & 1.968 & 1.520 & 1.688 \\
\hline
\end{tabular}


Table 3 Pearson correlation coefficient for porcine data

\begin{tabular}{|c|c|c|c|c|c|c|c|}
\hline vs. & miR-21 & miR-26a & miR-93 & miR-103 & miR-148a & miR-182 & miR-191 \\
\hline miR-26a & 0.930 & - & - & - & - & - & - \\
\hline$p$-value & 0.001 & - & - & - & - & - & - \\
\hline miR-93 & 0.909 & 0.984 & - & - & - & - & - \\
\hline$p$-value & 0.001 & 0.001 & - & - & - & - & - \\
\hline miR-103 & 0.880 & 0.973 & 0.995 & - & - & - & - \\
\hline$p$-value & 0.001 & 0.001 & 0.001 & - & - & - & - \\
\hline miR-148a & -0.407 & -0.323 & -0.206 & -0.180 & - & - & - \\
\hline$p$-value & 0.189 & 0.306 & 0.518 & 0.575 & - & - & - \\
\hline miR-182 & 0.860 & 0.904 & 0.868 & 0.879 & -0.506 & - & - \\
\hline$p$-value & 0.001 & 0.001 & 0.001 & 0.001 & 0.093 & - & - \\
\hline miR-191 & 0.898 & 0.993 & 0.986 & 0.982 & -0.311 & 0.902 & - \\
\hline$p$-value & 0.001 & 0.001 & 0.001 & 0.001 & 0.327 & 0.001 & - \\
\hline BestKeeper vs. & miR-21 & miR-26a & miR-93 & miR-103 & miR-148 & miR-182 & miR-191 \\
\hline coeff. of corr. [r] & 0.934 & 0.993 & 0.996 & 0.989 & -0.258 & 0.899 & 0.989 \\
\hline$p$-value & 0.001 & 0.001 & 0.001 & 0.001 & 0.421 & 0.001 & 0.001 \\
\hline
\end{tabular}

of miR-93 and miR-103 had the highest $r$ and $r^{2}$ values (Table 1). In porcine samples, miR-93, miR-26a, miR-191 and miR-103 had the highest $r$ and $r^{2}$ values (Tables 3,4 ).

\section{Optimal number of reference miRNAs}

To identify the optimum number of reference miRNAs, stepwise inclusion of the examined miRNAs was assessed. In the bovine samples, inclusion of the two most stable reference miRNAs yielded less variation than other combinations, and including more miRNAs did not improve the normalization factor (Fig. 2a). In porcine oocytes, the combination of three candidates showed the highest stability, although the difference with the use of 2 reference miRNAs was negligible (Fig. 2b).

Expression of the miRNAs miR-93 and miR-103 was subsequently used to normalize the expression levels of the other miRNAs and nuclear RNA analyzed in bovine samples (Fig. 3a-e). In porcine samples, normalization was performed using the relative expression of miR-26a, miR-191 and miR-93 (Fig. 4).

In bovine oocytes and embryos, all examined miRNAs showed an average expression stability below 1.5 (Fig. 1a) indicating relatively stable expression. Using the geometric mean of the identified reference miRNAs for normalization we therefore examined the expression of other miRNAs in oocytes and early embryos, namely Let-7b, miR-222 and miR-224 (Fig. 3f-h). Let-7b is a member of the Let-7 family of miRNAs shown to affect cell cycle molecules [39]. miR-222 was reported to be enriched in bovine mature oocytes and cumulus cells [22] and miR-224 has been shown to mediate the stimulatory effects of TGF $\beta 1$ on mouse granulosa cell proliferation by targeting Smad4, which is an important player in signal transduction of the TGF $\beta$ superfamily [40].

The 3 new miRNAs showed different expression patterns to the original panel examined. Let-7b was

Table 4 Regression analysis

\begin{tabular}{|c|c|c|c|c|c|c|c|}
\hline & miR-21 & miR-26a & miR-93 & miR-103 & miR-148a & miR-182 & miR-191 \\
\hline & vs. & vs. & vs. & vs. & vs. & vs. & vs. \\
\hline & BK & BK & BK & BK & BK & BK & BK \\
\hline coeff. of corr. [r] & 0.934 & 0.993 & 0.996 & 0.989 & -0.258 & 0.899 & 0.989 \\
\hline coeff. of det. $[r \wedge 2]$ & 0.872 & 0.986 & 0.992 & 0.978 & 0.067 & 0.808 & 0.978 \\
\hline intercept [CP] & -5.322 & -8.178 & -7.878 & -11.251 & 31.819 & 19.176 & -12.600 \\
\hline slope [CP] & 1.070 & 1.242 & 1.326 & 1.405 & -0.095 & 0.435 & 1.441 \\
\hline $\mathrm{SE}[C P]$ & \pm 1.111 & \pm 0.401 & \pm 0.323 & \pm 0.571 & \pm 0.96 & \pm 0.575 & \pm 0.585 \\
\hline$p$-value & 0.001 & 0.001 & 0.001 & 0.001 & 0.421 & 0.001 & 0.001 \\
\hline Power $[\mathrm{x}$-fold $]$ & 1.717 & 2.516 & 2.624 & 2.997 & 0.933 & 1.310 & 2.094 \\
\hline
\end{tabular}




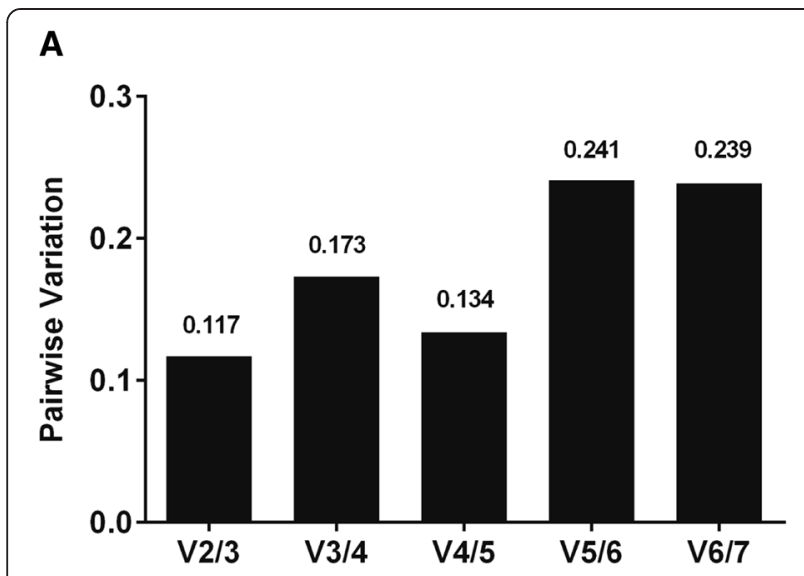

B

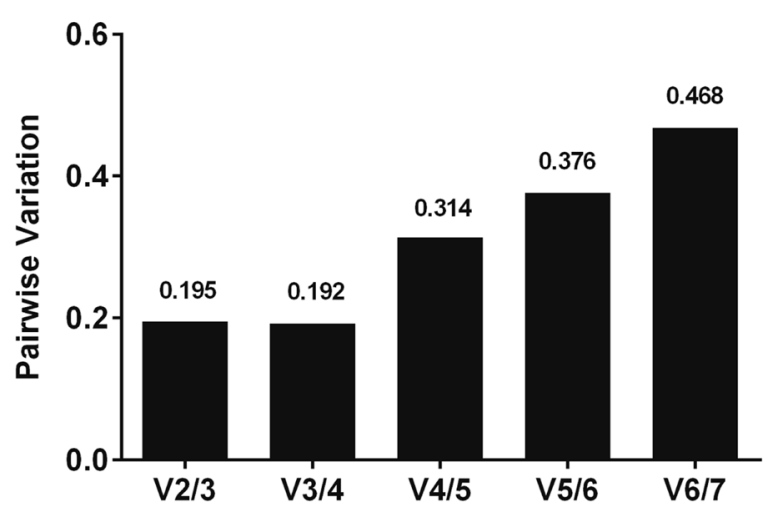

Fig. 2 Optimal number of reference miRNAs. Pairwise variation after successive inclusion of candidate reference miRNAs with lower stability using geNorm provided the optimal combination of miRNAs for normalization purposes. a In bovine oocytes and embryos, the use of two miRNAs was optimal. $\mathbf{b}$ In porcine oocytes and COCs the combination of three miRNAs was optimal, although the difference between using 2 or 3 miRNAs was negligible

expressed at highest levels in GV stage oocytes and was absent in blastocyst stage embryos (Fig. 3f). By contrast, expression of miR-222 was almost absent in GV stage oocytes but had significantly increased by the MII stage (Fig. 3g). The expression of miR-224 followed a pattern similar to that of Let 7b (Fig. 3h).

\section{Discussion}

When using qRT-PCR to compare gene expression levels, normalization using genes for which the expression does not vary appreciably between the cell types or stages is essential. Indeed, it is generally advised to normalize data acquired by qRT-PCR by using expression levels of more than one of these so-called reference genes $[25,41]$. Correct normalization is essential to rectify for differences in the efficiency of RNA isolation between samples, levels of RNA degradation, efficiency of
cDNA synthesis, amount of material processed and simple experimental variation. Historically, normalization of mRNA expression was performed with only one reference gene, often GAPDH. It has become clear, however, that for accurate normalization the use of several internal control genes is more reliable, and software such as geNorm and BestKeeper have been developed to help identify genes with the most stable expression levels.

The expression of reference genes can vary between different tissue types and the ideal reference genes should have constant expression levels in the tissue of interest irrespective of the experimental conditions. For analyzing the expression of miRNA in cells and tissues, however, the use of reference genes is likely to be suboptimal. There are several potential disadvantages of using genes (mRNA) or other nuclear RNAs for normalization of miRNA data. Firstly, these two groups (miRNAs vs mRNA/nuclear RNAs) have different pathways of biogenesis and are, by definition, different in nature. Secondly, there are significant size differences between miRNA and mRNA molecules which affects the methods and efficiency of RNA isolation and cDNA synthesis [38].

In contrast with methods for normalizing mRNA expression, little is known about the reliability of mRNA or miRNA for normalizing miRNA expression data. Our strategy was to select several potential candidates and examine their expression patterns using qRT-PCR, before using geNorm and BestKeeper to identify sets of miRNAs with the least variation for subsequent use as references for normalization.

There are various methods for normalization of expression levels. Expression levels can be calculated by relating the $C t$ values to each other, known as the $2^{-\Delta \Delta C t}$ method [42, 43]. Alternatively, the global mean of all expressed miRNAs can be considered as a normalizing factor [36, 37]. Here we incorporated amplification efficiency since relative expression was calculated using specific standard curves.

In the present study, the stability of expression of several miRNAs and a nuclear RNA, U6, previously reported for normalization of miRNA expression was tested in bovine and porcine oocytes and embryos. Using the geNorm conventions, we considered that expression could be considered 'stable' when the average expression stability was less than 1.5. In this study, all candidate miRNAs could thus be considered suitable for normalization of miRNA expression in bovine oocytes and preimplantation embryos ( $M$ values ranged from 0.28 to 1.1). In porcine COCs and oocytes only miR-184 did not meet the criteria for stability ( $\mathrm{M}$ value was 2.01 ). Among the different miRNAs however, miR-93 and miR-103, followed by miR-191, in bovine samples and miR-26a, miR-191 and miR-93 in porcine oocytes had the least variation and are 


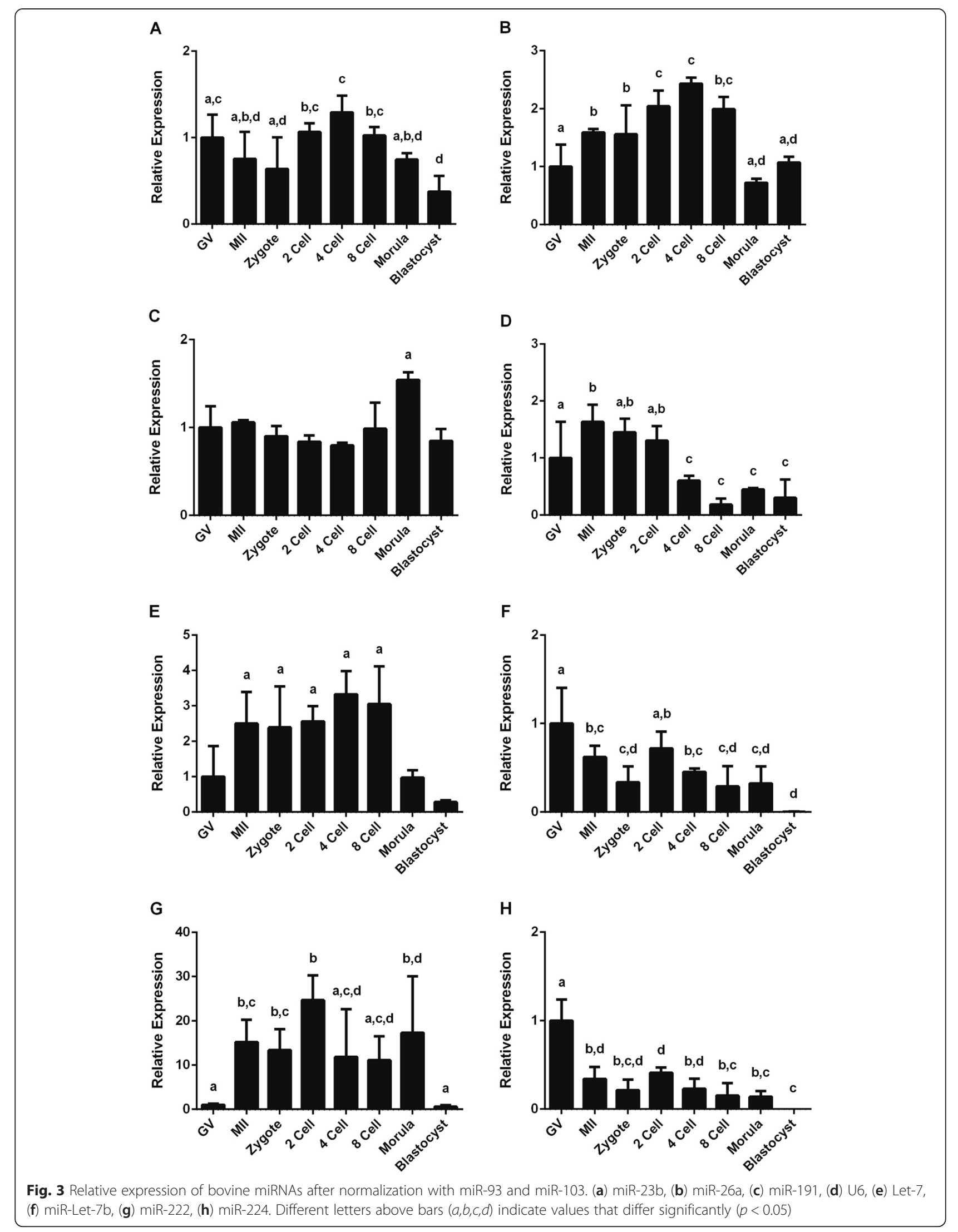


A

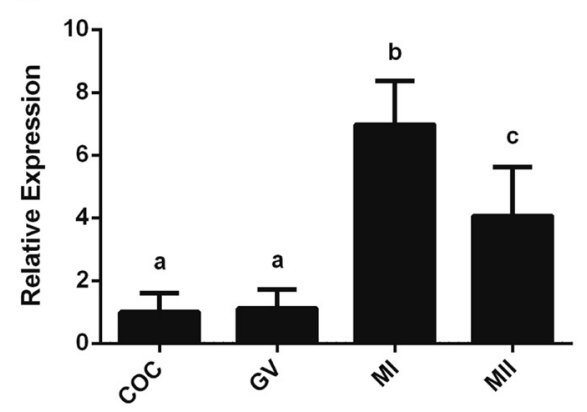

C

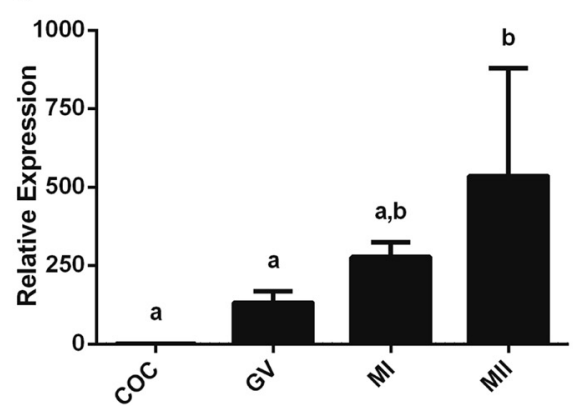

B

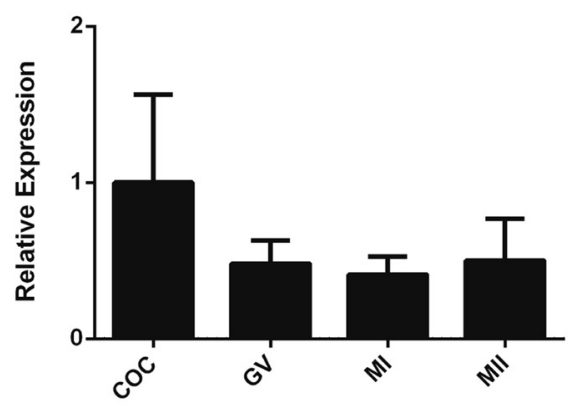

D

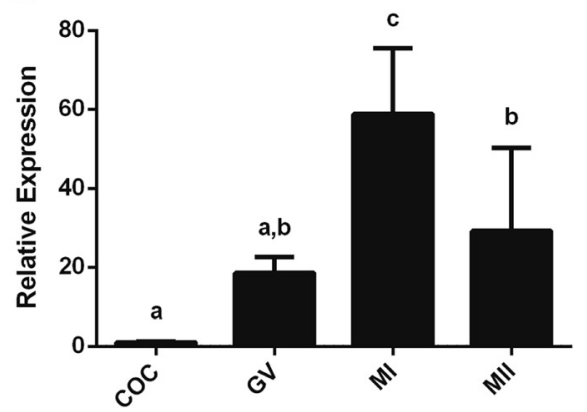

Fig. 4 Relative expression of porcine miRNAs after normalization with miR-26a, miR-191 and miR-93. (a) miR-21, (b) miR-103, (c) miR-148a, (d) miR-182. Different letters above bars $(a, b)$ indicate values that differ significantly $(p<0.05)$

therefore considered the most suitable for normalization. The expression of miR-21 in porcine cells was similar to that described previously with an increase in expression levels during maturation [44]

Here we have identified miRNAs that are expressed at a relatively constant level throughout normal oocyte and early embryo development. Abnormal or unstable expression of these miRNAs could indicate abnormal development. Although individual miRNA species can target multiple genes we had anticipated that the miRNAs that we had identified as reference would be more directed at genes in involved in basic cell biology. In silico analysis of the targets of the miRNAs suitable as reference versus those less suited did not reveal any obvious differences however, nor pointed at specific 'houskeeping' targets for the reference miRNAs (not shown).

Interestingly, miR-93 was reported to be a stable miRNA in human and porcine normal and cancerous solid tissues [32, 35]. In addition, the combination of miR-93 and miR-16 was found to be suitable for normalizing miRNA expression in the serum of gastric cancer patients and healthy controls [34]. miR-103 was proposed to be a stable miRNA in the porcine liver and uterus, but the least stable in the ovary [32], whereas it was considered unstable in rat tissues [45]. miR-191 was proposed as the best (most stable) miRNA data normalizer in the serum of human colorectal adenocarcinoma and colorectal adenoma patients [33], but had a lower stability ranking in rat tissues [45].

U6 is the major spliceosomal small nuclear RNA involved in processing of pre-mRNA [46] and although not a miRNA it is commonly used for normalization of miRNA expression [42, 43, 47]. We found expression of U6 to be unsuitable for normalization of miRNA expression in bovine oocytes and preimplantation embryos as its expression gradually decreased during the early cleavage stages. As there is little or no transcription before embryonic genome activation around the 8 cell stage this might reflect degradation of maternal RNA. This dynamics in U6 expression was similar to what has been described [19] We also found Let-7a to be the least stable miRNA in bovine oocytes and early embryos. This parallels reports in rat tissues and human serum where Let-7a expression was less stable than that of other candidates $[34,45]$.

\section{Conclusion}

Our results demonstrate interspecies variation in most suitable reference miRNAs and indicate the necessity of examining several potential miRNAs in different experimental models. The identification of a set of constantly expressed miRNAs will help us to better understand the function of miRNAs in the oocytes and preimplantation embryos. 


\section{Additional files}

Additional file 1: Figure S1. Expression of spiked-in UniSp6 added to RNA of the indicated cells and embryo stages. The expression level is plotted as threshold cycle (Ct).

Additional file 2: Figure S2. Absolute expression of candidate miRNAs in bovine oocytes and embryos. (A) miR-23b, (B) miR-26a, (C) miR-93, (D) miR103, (E) miR-191, (F) Let-7a, (G) U6.

Additional file 3: Figure S3. Absolute expression of candidate miRNAs in porcine oocytes. Left (1) graphs show all groups with the expression of cumulus-oocyte complexes (COC) set at 1; right (2) graphs show the same but the expression in germinal vesicle (GV) oocytes set at 1 and without COCs. (A) miR-21, (B) miR-26a, (C) miR-93, (D) miR-103, (E) miR-148a, (F) miR-182, (G) miR-191.

\section{Competing interests}

The authors declare that they have no competing interests.

\section{Authors' contribution}

MM executed the experiments, analyzed the data and co-wrote the manuscript. HTAT executed the experiments and analyzed the data. TAES analyzed the data. BAJR designed the study, analyzed the data and wrote the manuscript. All authors contributed to and approved the final version of the manuscript.

\section{Acknowledgements}

All members of the Roelen lab are thanked for helping collecting oocytes. MM was supported by the Iranian Ministry for Science, Research and Technology (42/5/33681).

Received: 3 February 2015 Accepted: 3 June 2015

Published online: 12 June 2015

\section{References}

1. Mclaren A. Germ cells and germ cell transplantation. Int J Dev Biol. 1998;860:855-60.

2. Li R, Albertini DF. The road to maturation: somatic cell interaction and self-organization of the mammalian oocyte. Nat Rev Mol Cell Biol. 2013;14:141-52.

3. Bounil C, Nguyen E, Debey P. Endogenous Transcription Occurs at the 1-Cell Stage in the Mouse Embryo. Exp Cell Res. 1995;218:57-62

4. Galán A, Montaner D, Póo ME, Valbuena D, Ruiz V, Aguilar C, et al. Functional genomics of 5- to 8-cell stage human embryos by blastomere single-cell cDNA analysis. PLoS One. 2010;5:e13615.

5. Hyttel P, Laurincik J, Rosenkranz C, Rath D, Niemann H, Ochs RL, et al. Nucleolar Proteins and Ultrastructure in Preimplantation Porcine Embryos Developed In Vivo. Biol Reprod. 1856;2000:1848-56.

6. Graf A, Krebs S, Heininen-Brown M, Zakhartchenko V, Blum H, Wolf E. Genome activation in bovine embryos: review of the literature and new insights from RNA sequencing experiments. Anim Reprod Sci. 2014;149:46-58.

7. Mraz M, Mayer J, Pospisilova S, Republic C. MicroRNA Biogenesis, Functionality and Cancer Relevance. Biomed Pap Med Fac Univ Palacky Olomouc Czech Repub. 2006;150:205-15.

8. Chen K, Rajewsky N. The evolution of gene regulation by transcription factors and microRNAs. Nat Rev Genet. 2007:8:93-103.

9. Bartel DP. MicroRNA Target Recognition and Regulatory Functions. Cell. 2013;136:215-33

10. Rodriguez A, Griffiths-Jones S, Ashurst JL, Bradley A. Identification of mammalian microRNA host genes and transcription units. Genome Res. 2004;14:1902-10.

11. Vasudevan S, Tong Y, Steitz JA. Cell cycle control of microRNA-mediated translation regulation. Cell Cycle. 2008;7:1545-9.

12. Bueno MJ, Malumbres M. MicroRNAs and the cell cycle. Biochim Biophys Acta. 1812;2011:592-601.

13. Suh N, Blelloch R. Small RNAs in early mammalian development: from gametes to gastrulation. Development. 2011;138:1653-61.

14. Sayed D, Abdellatif M. MicroRNAs in development and disease. Physiol Rev. 2011;91:827-87.

15. Dimopoulos K, Gimsing P, Grønbæk K. Aberrant microRNA expression in multiple myeloma. Eur J Haematol. 2013;91:95-105.

16. James CD. Aberrant miRNA expression in brain tumors: a subject attracting an increasing amount of attention. Neuro Oncol. 2013;15:405.
17. Lee TS, Jeon HW, Kim YB, Kim Y a, Kim M a, Kang SB. Aberrant microRNA expression in endometrial carcinoma using formalin-fixed paraffin-embedded (FFPE) tissues. PLoS One. 2013;8:e81421.

18. Kim YJ, Ku S-Y, Kim YY, Liu HC, Chi SW, Kim SH, et al. MicroRNAs transfected into granulosa cells may regulate oocyte meiotic competence during in vitro maturation of mouse follicles. Hum Reprod. 2013;28:3050-61.

19. Mondou E, Dufort I, Gohin M, Fournier E, Sirard M. Analysis of microRNAs and their precursors in bovine early embryonic development. Mol Hum Reprod. 2012;18:425-34.

20. Tang F, Kaneda M, O'Carroll D, Hajkova P, Barton SC, Sun YA, et al. Materna microRNAs are essential for mouse zygotic development. Genes Dev. 2007;21:644-8.

21. Yang C-X, Du Z-Q, Wright EC, Rothschild MF, Prather RS, Ross JW. Small RNA profile of the cumulus-oocyte complex and early embryos in the pig. Biol Reprod. 2012;87:117.

22. Abd El Naby WS, Hagos TH, Hossain MM, Salilew-Wondim D, Gad a Y, Rings F. Expression analysis of regulatory microRNAs in bovine cumulus oocyte complex and preimplantation embryos. Zygote. 2013;21:31-51.

23. Suh N, Baehner L, Moltzahn F, Melton C, Shenoy A, Chen J, et al. MicroRNA function is globally suppressed in mouse oocytes and early embryos. Curr Biol. 2010;20:271-7.

24. Bustin SA. Quantification of mRNA using real-time reverse transcription PCR (RT-PCR): trends and problems. J Mol Endocrinol. 2002;29:23-39.

25. Vandesompele J, De Preter K, Pattyn F, Poppe B, Van Roy N, De Paepe A, et al. Accurate normalization of real-time quantitative RT-PCR data by geometric averaging of multiple internal control genes. Genome Biol. 2002;3: research0034.1-0034.11.

26. Brattelid T, Aarnes EK, Helgeland E, Guvaåg S, Eichele H, Jonassen AK. Normalization strategy is critical for the outcome of miRNA expression analyses in the rat heart. Physiol Genomics. 2011;43:604-10.

27. Bustin SA, Benes V, Garson JA, Hellemans J, Huggett J, Kubista M, et al. The MIQE guidelines: minimum information for publication of quantitative real-time PCR experiments. Clin Chem. 2009;55:611-22.

28. Van Tol HTA, van Eerdenburg FJCM, Colenbrander B, Roelen BAJ. Enhancement of Bovine oocyte maturation by leptin is accompanied by an upregulation in mRNA expression of leptin receptor isoforms in cumulus cells. Mol Reprod Dev. 2008;75:578-87.

29. Algriany O, Bevers M, Schoevers E, Colenbrander B, Dieleman S. Follicle size-dependent effects of sow follicular fluid on in vitro cumulus expansion, nuclear maturation and blastocyst formation of sow cumulus oocytes complexes. Theriogenology. 2004;62:1483-97.

30. Pfaffl MW, Tichopad A, Prgomet C, Neuvians TP. Determination of stable housekeeping genes, differentially regulated target genes and sample integrity: BestKeeper - Excel-based tool using pair-wise correlations. Biotechnol Lett. 2004;26:509-15.

31. Shen Y, Li Y, Ye F, Wang F, Wan X, Lu W, et al. Identification of miR-23a as a novel microRNA normalizer for relative quantification in human uterine cervical tissues. Exp Mol Med. 2011;43:358-66.

32. Timoneda O, Balcells I, Córdoba S, Castelló A, Sánchez A. Determination of reference microRNAs for relative quantification in porcine tissues. PLoS One. 2012;7:e44413.

33. Zheng G, Wang $H$, Zhang $X$, Yang $Y$, Wang L, Du L, et al. Identification and validation of reference genes for $\mathrm{GPCR}$ detection of serum microRNAs in colorectal adenocarcinoma patients. PLoS One. 2013;8:e83025.

34. Song J, Bai Z, Han W, Zhang J, Meng H, Bi J, et al. Identification of suitable reference genes for $\mathrm{QPCR}$ analysis of serum microRNA in gastric cancer patients. Dig Dis Sci. 2011:57:897-904.

35. Peltier HJ, Latham GJ. Normalization of microRNA expression levels in quantitative RT-PCR assays : Identification of suitable reference RNA targets in normal and cancerous human solid tissues Normalization of microRNA expression levels in quantitative RT-PCR assays : Identifica. RNA. 2008;14:844-52.

36. Mestdagh P, Van VP, De WA, Muth D, Westermann F, Speleman F, et al. A novel and universal method for microRNA RT-qPCR data normalization. Genome Biol. 2009;10:R64.

37. Chang KH, Mestdagh P, Vandesompele J, Kerin MJ, Miller N. MicroRNA expression profiling to identify and validate reference genes for relative quantification in colorectal cancer. BMC Cancer. 2010;10:173.

38. Schaefer A, Jung M, Miller K, Lein M, Kristiansen G, Erbersdobler A, et al. Suitable reference genes for relative quantification of miRNA expression in prostate cancer. Exp Mol Med. 2010;42:749. 
39. Schultz J, Lorenz P, Gross G, Ibrahim S, Kunz M. MicroRNA let-7b targets important cell cycle molecules in malignant melanoma cells and interferes with anchorage-independent growth. Cell Res. 2008;18:549-57.

40. Yao G, Yin M, Lian J, Tian H, Liu L, Li X, et al. MicroRNA-224 is involved in transforming growth factor-beta-mediated mouse granulosa cell proliferation and granulosa cell function by targeting Smad4. Mol Endocrinol. 2010;24:540-51.

41. Hellemans J, Mortier G, De Paepe A, Speleman F, Vandesompele J. qBase relative quantification framework and software for management and automated analysis of real-time quantitative PCR data. Genome Biol. 2007;8:R19.

42. Choong ML, Yang HH, McNiece I. MicroRNA expression profiling during human cord blood-derived CD34 cell erythropoiesis. Exp Hematol. 2007;35:551-64.

43. Corney DC, Flesken-Nikitin A, Godwin AK, Wang W, Nikitin AY. MicroRNA-34b and MicroRNA-34c are targets of p53 and cooperate in control of cell proliferation and adhesion-independent growth. Cancer Res. 2007;67:8433-8.

44. Wright EC, Yang C-X, Scanlon R, Selman B, Ross J. MicroRNA-21 and PDCD4 Expression During In Vitro Maturation of Porcine Oocytes. Biol Reprod. 2010;83:322.

45. Lardizábal MN, Nocito AL, Daniele SM, Ornella L a, Palatnik JF, Veggi LM. Reference genes for real-time PCR quantification of microRNAs and messenger RNAs in rat models of hepatotoxicity. PLoS One. 2012;7:e36323.

46. Kiss T. Biogenesis of small nuclear RNPs. J Cell Sci. 2004;117(Pt 25):5949-51.

47. Shell S, Park S-M, Radjabi AR, Schickel R, Kistner EO, Jewell D a. Let-7 expression defines two differentiation stages of cancer. Proc Natl Acad Sci U S A. 2007;104:11400-5.

\section{Submit your next manuscript to BioMed Central and take full advantage of:}

- Convenient online submission

- Thorough peer review

- No space constraints or color figure charges

- Immediate publication on acceptance

- Inclusion in PubMed, CAS, Scopus and Google Scholar

- Research which is freely available for redistribution 